\title{
Megaciudad Buenos Aires: Cartografía de su última expansión y conurbación mediante el procesamiento digital de imágenes satelitales nocturnas
}

\author{
Megacity Buenos Aires: Cartography of its lastest \\ expansion and conurbation with digital processing of \\ nocturnal sattellite images
}

\author{
Gustavo D. Buzai* \\ Eloy Montes Galbán**
}

Recibido 20 de diciembre de 2019; aceptado 30 de enero de 2020

\section{Resumen}

El procesamiento digital de imágenes satelitales nocturnas y el uso de Sistemas de Información Geográfica confirma que la última expansión y conurbación de la Megaciudad Buenos Aires se produjo con el cambio de siglo. Esto se verifica al analizar un período de dos décadas (1992-2012) con centralidad en el año 2002. Si bien la estabilización del crecimiento de la Megaciudad Buenos Aires comenzó hace cinco décadas, el análisis temporal de imágenes y la realización de cartografía temática permitieron representar espacialmente un nuevo proceso de conurbación. Este proceso se desarrolló en cinco ejes de expansión incorporando otras ciudades de la región metropolitana cuya distancia media al centro principal es de $61 \mathrm{~km}$. Las imágenes satelitales nocturnas brindan nuevas perspectivas del espacio urbano al utilizarse los conceptos de megaciudad, expansión urbana, conurbación e infraestructura gris. A través de los elementos que brinda el área urbana consolidada, la urbanización difusa

* Universidad Nacional de Luján, Argentina, correo electrónico: gdb@unlu.edu.ar. ORCID: https://orcid.org/0000-0003-4195-5324.

** Universidad Nacional de Luján, Argentina, correo electrónico: emontesgalban@gmail.com. ORCID: https://orcid.org/0000-0002-4075-4873. 
y la mayor densidad y proporción de las vías de comunicación dan la posibilidad de captar configuraciones actuales y disponer de elementos para captar tendencias espaciales futuras.

Palabras clave: Megaciudad, Buenos Aires, expansión urbana, imágenes satelitales nocturnas, Cartografia Digital.

\begin{abstract}
Digital processing of nocturnal satellite images and the use of Geographical Information Systems confirms that the last expansion and conurbation of the Megacity Buenos Aires occurred with the turn of the century. This is verified by analyzing a period of two decades (1992-2012) with centrality in 2002. Although the stabilization of the growth of the Megacity Buenos Aires began five decades ago, the temporal analysis of images and the realization of thematic cartography allowed a spatial representation of a new conurbation process. This process was developed in five axes of expansion incorporating other cities in the metropolitan region whose average distance to the main center is $61 \mathrm{~km}$. The nocturnal satellite images provide new perspectives of the urban space when the concepts of megacity, urban expansion, conurbation and gray infrastructure are used. Through the elements provided by the consolidated urban area, diffuse urbanization and the greater density and proportion of communication channels we have the possibility of capturing current configurations and count with elements to foresee future spatial trends.

Key words: Megacity; Buenos Aires, urban sprawl, nocturnal satellite images, digital cartography.
\end{abstract}

\title{
Introducción
}

De acuerdo al último reporte The World's Cities publicado por Naciones Unidas (UN, 2018) hay actualmente 33 megaciudades en el mundo, aglomeraciones urbanas que superan los 10000000 de habitantes. América Latina cuenta con seis: São Paulo, Brasil (21 650 000), Ciudad de México, México (21 580 000), Buenos Aires, Argentina (14 967.000 ), Río de Janeiro, Brasil (13 293 000), Bogotá, Colombia (10 574 000) y Lima, Perú (10 391 000).

En estas megaciudades pueden verificarse los mayores efectos de la globalización en lo económico al orientarse hacia los mercados globales, en lo político a través de políticas de desregulación, en lo social en la polarización socio-espacial y en lo ecológico a la mayor probabilidad de riesgos (Borsdorf y Coy, 2009). Desde un punto de vista físico son las mayores extensiones de superficie urbana construida, aglomeraciones de miles de $\mathrm{km}^{2}$ que se encuentran estructuradas con la totalidad de elementos tradicionales y actuales que permiten su funcionalidad. Desde sus comienzos 
hasta hoy y desde el centro hasta sus bordes combina estructuras en permanente evolución.

Uno de los aspectos donde más ha centrado la atención respecto a la evolución espacial de las megaciudades son sus extensas periferias. Inicialmente la extensión física de la ciudad central, luego el proceso de conurbación que la fusiona físicamente con ciudades cercanas y finalmente la mejora en las vías de comunicación para extenderla y permitir la creación de barrios cerrados destinado a grupos sociales ligados a las actividades económicas del CBD (Central Business District) como centro de primer orden en la jerarquía de centros intraurbanos. Finalmente, algunas megaciudades desarrollan exociudades dentro de la trama urbana periférica, ciudades exteriores con semi-autonomía y, de esta manera su espacio exterior comienza a funcionar fragmentado en polígonos delimitados que concentran empleos de nivel terciario y cuaternario con viviendas y servicios esenciales en un paisaje general propio del CBD.

En este contexto, el presente trabajo tiene por objetivo analizar la última gran expansión que se produjo en la Megaciudad Buenos Aires, situación con la cual hizo su ingreso al siglo XXI. Corresponde a un amplio proceso de conurbación en los bordes más alejados fusionando cinco ciudades tradicionalmente separadas y con ello la Megaciudad Buenos Aires amplía su superficie y cantidad de habitantes en un salto cualitativo y cuantitativo de gran significancia.

Este aspecto que pudimos comenzar a delinear a partir del papel preponderante que tomó la infraestructura gris ${ }^{1}$ en la región, de la evidencia empírica visual a partir de trayectos realizados y vuelos fotográficos en el marco de un proyecto de investigación previo (Buzai y Lanzelotti, 2019) pudimos comprobarlo a través del uso de técnicas geoinformáticas.

El procesamiento digital de imágenes satelitales nocturnas, junto al modelado cartográfico y la cartografía digital síntesis realizada mediante un Sistemas de Información Geográfica (SIG) nos permitió comprobar que la conurbación se había producido entre los años 1992 y 2002 y consolidado en 2012, llevando el límite más extenso de la megaciudad a $90 \mathrm{~km}$ del CBD de la ciudad central.

En los puntos siguientes se presenta el marco teórico que sustenta conceptualmente la investigación y los desarrollos de modelos urbanos para el estudio de las grandes ciudades de América Latina, el marco metodológico en donde se presenta una revisión documental de la utilización de imágenes satelitales nocturnas para el estudio del crecimiento urbano, características de los datos utilizados, las técnicas asociadas para su tratamiento y aspectos cartográficos, y finalmente se presenta la

1 La infraestructura gris o infraestructura construida son sistemas de construcción humana (artificiales) que brindan soporte a la comunidad como las carreteras y otros sistemas de transporte como el de gestión de aguas pluviales y diversos servicios públicos (Benedict y McMahon, 2006). 
aplicación, en la cual se incluye la cartografía producida mediante el tratamiento de las imágenes satelitales nocturnas y el mapa final, síntesis de la comprobación y base para la interpretación del nuevo proceso de expansión.

\section{Perspectiva sistémica en focalización espacial}

\section{Marco conceptual}

Las distribuciones espaciales no se producen de manera aleatoria, sino que pueden asociarse a comportamientos generales que permiten llegar a la formulación de modelos y leyes para explicar la organización del territorio. Desde un punto de vista sistémico los estudios geográficos intentan descubrir regularidades que permitan comprender el comportamiento espacial.

Conocer estas leyes, da la posibilidad de realizar predicciones teóricas respecto de las configuraciones espaciales futuras en el marco de una Geografía Aplicada prospectiva a partir de considerar relaciones causales que permiten modelar escenarios futuros.

La investigación científica tiene como objetivo estudiar elementos específicos de la realidad y, principalmente, sus espacios relacionales. De esta manera, una tarea inicial es realizar una clara demarcación del campo de estudio a partir de definir totalidades estructuradas como sistemas.

Un marco de abordaje es la teoría general de los sistemas (TGS) formulada por Bertalanffy (1968) como construcción global que avanza empíricamente en el estudio de elementos y relaciones con el objetivo de encontrar similitudes modelísticas en estructuras de diferentes recortes de la realidad. De esta manera se ponen en evidencia aspectos matemáticos que pueden ser utilizados para estudiar y describir comportamientos en diferentes escalas. Los estudios geográficos centran su análisis en la escala humana y, dentro de ella, en el nivel espacial.

Un sistema se explica a través de su estructura general. La TGS permite unir diferentes elementos que provee la especialización científica y brinda posibilidades para un análisis global. El abordaje en el estudio de la organización del territorio permite obtener resoluciones a través del uso de las matemáticas como lenguaje de la ciencia, y la geometría como lenguaje de la forma espacial.

La consideración de especificidades que emergen en diferentes escalas fue la base para la formulación de la teoría de los sistemas complejos (TSC) sistematizada por García (2006). Este avance demostró importantes capacidades en dos niveles principales del análisis geográfico: en el estudio de la organización territorial y en la construcción de conocimientos en base al alcance epistemológico de los diferentes paradigmas de la Geografía.

Estas capacidades resultan posibles porque concibe una realidad organizada de manera estratificada a partir de niveles con funcionamientos semi-autónomos. Puede 
considerarse que entre lo infinitamente grande (espacio sideral) y lo infinitamente pequeño (espacio microscópico) está la escala humana (Rosnay, 1977) donde la Geografía pone atención. Al aplicar la TSC al estudio de la organización territorial se realizan abordajes que podrían desembocar en tres niveles, uno focal que sería el de resolución propio de la temática (el espacio geográfico), uno supra-focal (escala mundial) de mayor amplitud y uno infra-focal (escala personal) de mayor nivel de detalle.

El paradigma cuantitativo que apoya el análisis espacial con SIG brinda la base metodológica para el nivel focal. Sus estudios abordan en aspectos concretos y visibles, por lo que, como actividad científica, se basa en los supuestos centrales del materialismo sistémico (Bunge, 2012) que establece que la realidad existe independientemente de cómo se la piense (realismo), que puede ser estudiada a través de su materialidad (materialismo), que estos elementos tienen relaciones sistémicas (sistemismo) y que la forma de mayor aptitud para aprehenderlo es la ciencia (cientificismo) en el marco de la Ciencia Aplicada y, en nuestro caso, de la Geografía Aplicada con intención de captar una nueva instancia en la conformación de la Megaciudad Buenos Aires.

\section{Marco metodológico}

La Geografía como disciplina científica y, más específicamente, la Geografía Urbana, permite observar de qué manera los métodos y técnicas que se aplican al estudio del espacio urbanizado fueron evolucionando a la par de los avances geotecnológicos. La Geografía forma parte de la actual revolución geotecnológica especialmente en lo referente a la generación, acceso y manejo de información geográfica digital (Montes Galbán, 2017).

El paradigma de la Geografía Cuantitativa avanza en la década de 1980 hacia la Geografía Automatizada (Dobson, 1983) en un proceso continuo de incorporación de las técnicas geográficas de base racionalista y cuantitativa al ambiente informático. Esta evolución, que ya lleva muchas década (Buzai, 2015a), logra gran estabilidad a partir de la década del 2000, momento en que los diferentes software adquieren excelente compatibilidad con la finalidad de compartir información geográfica $(\mathrm{Bu}-$ zai y Ruiz, 2012).

Las tecnologías digitales en la actualidad presentan una gran variedad de posibilidades de aplicación y los SIG toman el lugar de pivote de integración para facilitar la obtención de resultados a partir de la convergencia creativa.

La valorización generalizada de estas aplicaciones ha sido muy importante y su prestigio creció al mismo tiempo que la mayoría de las ciencias muestran interés en la incorporación de la dimensión espacial en sus estudios.

La transformación del mundo real en un modelo digital con posibilidades de ser trabajado mediante procedimientos computacionales, exige una serie de operaciones 
de estandarización que finalizan al nivel de byte. Mediante estas transformaciones, que se encuentran compuestas por procesos de fragmentación y estandarización de la información espacial, todo objeto geográfico puede definirse digitalmente a través de una geometría particular (en estructura vectorial: punto, línea y polígono. En estructura raster: celda), una localización precisa en el espacio absoluto ( $x-y$ o geográficas), una serie de atributos (en estructura vectorial: variables. En estructura raster: número digital) y su existencia en un punto del eje temporal.

En sistema vectorial, la concreción de estos aspectos se realiza a través de la creación de bases de datos alfanuméricas y bases de datos gráficas y, para ello, existe software específico destinado al tratamiento de datos georrefenciados. Los primeros orientados a los procedimientos numéricos (planillas de cálculo, programas de análisis estadístico) y los segundos a la geometría (diseño asistido por computador, cartografía automatizada). Mediante esta organización se aplican procedimientos del análisis multivariado.

En el sistema raster el número digital (característica clasificatoria de la entidad) se ubica matricialmente en el mismo nivel de la celda que representa, por lo tanto la geometría y el número único son inseparables. Mediante esta organización se aplican procedimientos del procesamiento digital de imágenes satelitales y el modelado cartográfico a través del álgebra de mapas.

Actualmente los SIG combinan la totalidad de posibilidades de procesamiento de datos $y$, en este sentido, podemos ver como en el presente trabajo son un claro nexo entre el procesamiento digital de imágenes satelitales nocturnas de áreas urbanas y la representación en cartografía temática.

Considerando su aplicación al estudio del espacio geográfico como sistema complejo vemos que se apoyan en una focalización espacial. Todo análisis en el cual intervengan cuestiones sociológicas, económicas, políticas o culturales son plausibles de tratamiento siempre considerando su manifestación espacial. La aplicación apoya el materialismo sistémico porque aborda la realidad desde un punto de vista empírico, a través de su materialidad en relaciones modelísiticas y sistémica, con metodología propias de la ciencia aplicada.

\section{Modelos urbanos hacia la megaciudad en América Latina}

\section{Modelos urbanos}

Cuando los modelos urbanos clásicos (anillos de Burgess, 1925; sectores de Hoyt, 1939; núcleos múltiples de Harris y Ullman, 1945) son utilizados para explicar la realidad de las ciudades de América Latina, si bien los patrones geométricos de organización generan similares configuraciones espaciales el contenido correspondiente al mapa social es diferente. 
Esta situación la había señalado inicialmente Schnore (1965) surgiendo que no era posible aplicar con éxito el modelo secuencial propuesto por Sjoberg (1960), el cual basa su análisis en el cambio de organización espacial que lleva el paso de la ciudad pre-industrial a la ciudad industrial. Las ciudades de América Latina presentan un mapa social inverso al de las ciudades de América Anglosajona (Buzai, 2014, 2015 b) y este sería el aspecto distintivo sobre el cual se basarían los nuevos modelos urbanos.

Los modelos surgidos de las ciudades de América Latina muestran una inicial ciudad compacta al estructurarse en anillos y sectores y, en esta configuración, Griffin y Ford (1980) destacan la principal característica del mapa social: condiciones socio-económicas favorables que disminuyen hacia la periferia. En este proceso, notable durante la segunda mitad del siglo XX, el CBD concentra la mayor parte de la oferta de bienes y servicios de alta especificidad como centro principal. Asimismo, las actividades del comercio al por menor se expanden de manera lineal a partir de alguna importante vía de circulación (spine), situación que es acompañada por el desplazamiento sectorial de grupos sociales de alto nivel socioeconómico sobre una base de tres anillos que surgen desde el centro.

Una década y media después Ford (1996) amplía el modelo a partir de incorporar nuevos procesos en el centro como la gentrificación y en la periferia como la aparición de una avenida de circunvalación (tomado del modelo Periférico de Ciudad de México), la aparición del Mall en el extremo de la expansión lineal comecial (spine) y el parque industrial en diferente ubicación periférica. La experiencia muestra que el modelo en su versión inicial se ajusta muy bien al caso de las ciudades de tamaño intermedio y su modificación lo asimila a las grandes ciudades.

Modelos orientados hacia la estructura espacial de las grandes ciudades de América Latina estuvieron formulados inicialmente por Bähr (1976) y Mertins (1980) que dieron como resultado final la confluencia presentada en Bähr y Mertins (1982) y, junto a ellos, también debe ser considerado el aporte realizado por Borsdorf (1982) y su actualización en Borsdorf (1994). Tomando como referencia la aglomeración de Buenos Aires, Janoschka (2002) propone el modelo de ciudad de islas, una estructuración espacial que corresponde a la visión de archipiélagos urbanos formados por islas de riqueza en mares de pobreza (Berry, 1985; Borsdorf y Coy, 2009).

En la ciudad fragmentada se destaca el notable impacto de los flujos migratorios en el crecimiento poblacional y la expansión física de la ciudad. En su evolución histórica pueden verse varias estructuras superpuestas: 1) Iniciales anillos concéntricos a partir del CBD, 2) estructura moderna sectorial de expansión por ejes de crecimiento y 3) estructura periférica celular formada principalmente por asentamientos informales y proyectos gubernamentales de viviendas, apareciendo incipientemente barrios cerrados de alto nivel económico. Surgen extensas y heterogéneas periferias como el rasgo más notable de la megaciudad. 


\section{Periferias urbanas actuales}

El espacio periurbano, la franja marginal urbano-rural (Carter, 1983) es uno de los más complejos de la ciudad, ya que allí se superponen los servicios ambientales que llegan del ámbito rural y los servicios urbanos que se extienden desde el centro de la ciudad, ambos en una proporción de sus máximas posibilidades.

La ciudad compacta evolucionó hacia la ciudad difusa y al archipiélago urbano (Indovina, 2009) producto de la acelerada expansión urbana (urban sprawl) lejana al centro principal de la ciudad. Desde mediados del siglo pasado, esta expansión fue característica de las ciudades norteamericanas a partir de amplios loteos periféricos, la construcción de autopistas y la masividad en la propiedad automotor. La proporción relativa en la distribución poblacional permitió considerar una contraurbanización (Berry, 1976) y aparecen manchones periféricos que generan algunas problemáticas sociales al ser el soporte de una segregación poblacional (Whyte, 1958).

El proceso de expansión urbana se desarrolló de manera ininterrumpida hasta la actualidad (Mitchell, 2001) generando diferentes visiones socio-espaciales de un espacio geográfico sobre el cual resulta complicado establecer límites precisos demarcatorios entre lo urbano y rural.

El caso de Buenos Aires es paradigmático y fue tomado como ejemplo de la evolución de las grandes ciudades de América Latina en el marco de la globalización y del avance del liberalismo económico en la región. Si bien la aglomeración había comenzado un proceso de estabilidad en su valor superficial a partir de la década de los setenta (Buzai y Baxendale, 1998) a partir de mediados de la década de 1los noventa comienza a tomar el modelo de ciudad norteamericana ante la aparición de las urbanizaciones cerradas (country clubs) como polígonos residenciales y la creación de autopistas que las conectan con la ciudad central, la Ciudad Autónoma de Buenos Aires. Esto permite ver el desplazamiento suburbano de los grupos de alto nivel socio-económico que comienzan a segregarse (Buzai, 1992) y a generar sus principales actividades diarias en espacios cerrados vinculados por autopistas. La totalidad de espacios comienzan a ser no-lugares con paisajes similares en cualquier importante ciudad del mundo que experimente los mismos procesos (Auge, 2017).

En cuanto al mapa social, Buenos Aires presenta el modelo de ciudad pre-industrial en su momento de máxima industrialización en 1945 y toma el modelo de ciudad industrial cuando es evidente su disminución industrial a partir de 1990 (Buzai y Marcos, 2012). Se aprecian características de suburbia (Bauer, 1993) en una mezcla de proyectos de monoblocks de gestión pública y el impuso de los desarrolladores privados en espacios habitacionales y empresariales.

Este crecimiento urbano genera efectos irreversibles al afectar la resiliencia de los ecosistemas de entorno y que son de utilidad para la sostenibilidad del hábitat humano. La aglomeración de Buenos Aires produce efectos negativos sobre la llanura pampeana y el bosque ribereño, espacios que merecerían cuidado por sus servicios 
ambientales, diversidad de especies y variados paisajes. Estos efectos pueden verse en la huella paisajística (Morello et al., 2001) con clara evidencia a distancias de la ciudad central de entre 35 y $70 \mathrm{~km}$.

Desde un punto de vista espacial, en esta franja se verifica una notable irregularidad y fragmentación en los bordes de la aglomeración, aspecto que pudo ser estudiado mediante la geometría fractal con la finalidad de captar la verdadera forma y patrones de crecimiento urbano (Batty y Longley, 1994), geometría aplicada a la aglomeración de Buenos Aires por Buzai, Lemarchand y Schuschny (1998) con fines de modelización de su expansión con autómatas celulares.

La fragmentación espacial y social en las periferias urbanas actuales es uno de los signos distintivos de la posmetrópolis (Soja, 2000).

\section{Metodología}

\section{Imágenes satelitales nocturnas: revisión documental}

Cuando se efectúa una primera revisión documental del uso de imágenes satelitales nocturnas en Geografía, es posible acceder a algunas publicaciones de divulgación científica general, que desde hace más de dos décadas muestran su aplicación en proyectos de investigación a nivel planetario, este es el caso de los mapas publicados por la National Geographic $(1998,2004)$. Estos mosaicos del planeta se construyeron en base a datos satelitales de luces nocturnas reunidos a lo largo de un año, en el cual se pueden identificar las regiones del planeta con grandes áreas urbanas mostrando un intenso brillo de luz blanca, por otro lado, también destacan los grandes incendios, las locaciones con combustiones de gas y la pesca nocturna.

De igual manera, está el "Proyecto Huella Humana" desarrollado por la Wildlife Conservation Society (WCS) y el Center for International Earth Science Information Network (CIESIN), su resultado permitió representar en un mapa global los niveles de influencia antrópica en el planeta (especialmente sobre la vida salvaje y tierras vírgenes), uno de los factores considerados para la construcción de este mapa, fueron las redes de energía, que se midieron a través de las imágenes satelitales que perciben luces por la noche, puesto que es un indicador adecuado para la identificación de la infraestructura energética (National Geographic, 2005).

Las investigaciones que utilizan imágenes satelitales nocturnas y que buscan dar cuenta de las actividades humanas son cada vez más abundantes y diversas entre las cuales podemos mencionar aplicaciones en una importante variedad de temas que contemplan la relación entre la sociedad y el medio físico-natural (Montes Galbán, 2019). Específicamente podemos nombrar aplicaciones urbanas en Henderson et al. (2003) quienes mencionan las dificultades de establecer un umbral de intensidad lumínica para su definición; en esta línea, otros trabajos intentaron realizar validaciones con otras fuentes satelitales (Small et al., 2005; Potere et al., 2009). A pesar de las 
complejidades y limitaciones metodológicas se continua avanzando en el tema para la identificación, delimitación y monitoreo del crecimiento de las áreas urbanas a partir de las imágenes nocturnas, incrementándose los aportes científicos provenientes de diferentes continentes, América (Mitchell, 2001; Amaral et al., 2006; Pérez Machado et al., 2014; Martin Oriol, 2016), Asia (Roy Chowdhury et al., 2012; Liu \& Leung, 2015; Xin, et al., 2017; Kamarajugedda et al., 2017), Europa (Nel.lo et al., 2016; Nel.lo et al., 2017; Checa et al., 2017; Checa \& Nel. 1o, 2018) y estudios comparativos entre regiones del planeta (Zhou et al., 2015).

Los antecedentes de la referida temática en Argentina y en el área que atañe a la presente investigación no son abundantes. Se puede mencionar una propuesta metodológica a escala nacional que tuvo como objetivo identificar las áreas intermedias entre los usos urbano y rurales, con este fin se consideraron entre los materiales las imágenes satelitales nocturnas (Quaíni, 2014); un antecedente más reciente es el trabajo desarrollado por Martin Oriol (2016), quien realizó un estudio comparativo entre las urbes de Buenos Aires y Lima, analizando los cambios en la forma urbana a través de imágenes nocturnas de satélite; por último, desarrollamos una primera aproximación utilizando imágenes del satélite Suomi NPP (compuestos anuales) ofrecidas por la National Oceanic and Atmospheric Administration (NOAA) para estimar el porcentaje de superficie iluminada en los partidos de la cuenca del río Luján (Montes Galbán, 2019), y evaluar la expansión y densificación del Gran Buenos Aires en el período 2012-2019 (Montes Galbán, 2020).

\section{Información básica - Fuente de datos satelitales}

Los datos primarios utilizados en la investigación provienen de tres fuentes. La principal está referida a las imágenes de la Tierra por la noche producidas por el Grupo de Observaciones de la Tierra (Earth Observation Group -EOG por sus siglas en inglés), que forma parte del Centro Nacional de Datos Geofísicos (NGDC por sus siglas en inglés) de la Administración Nacional Oceánica y Atmosférica de los Estados Unidos (NOAA por sus siglas en inglés). Dichas imágenes son una composición que es posible gracias a los sensores denominados OLS (Operational Linescan System - Sistema Operacional en Línea) a bordo de la serie de satélites DMSP del Programa de Satélites Meteorológicos del Ministerio de Defensa de los Estados Unidos (Defense Meteorological Satellite Program). ${ }^{2}$

Los datos que presenta el EOG disponibles para su descarga en su versión $4^{3}$, son cuadrículas de 30 segundos de arco, que abarcan desde -180 a 180 grados de longitud

2 La creciente demanda de los productos de iluminación nocturna por una amplia variedad de usuarios (científicos de uso del suelo, geógrafos urbanos, ecólogos, astrónomos, demógrafos, economistas y científicos sociales) ha propiciado el desarrollo de algoritmos para la generación de productos de luces nocturnas globales de alta calidad (Elvidge et al., 2017).

3 Entre la variedad de productos que el Centro Nacional de Datos Geofísicos pone a disposición para su descarga están los compuestos anuales DMSP-OLS Nighttime Lights Time Series en su versión 4 
y -65 a 75 grados de latitud. Dichas cuadrículas tienen una resolución aproximada de 760 x 760 metros (en la latitud que corresponde al área estudiada) y están disponibles en formato GeoTIFF (Tabla 1). Para los efectos de la presente aplicación se descargaron las imágenes con una cobertura a intervalos temporales de diez años: 1992, 2002 y 2012.

Tabla 1

Características del DMSP-OLS y las imágenes utilizadas

\begin{tabular}{ll}
\hline \multicolumn{1}{c}{ Características } & \multicolumn{1}{c}{ Descripción } \\
\hline Cuantificación radiométrica & 6 bits \\
Valores de luminosidad & 0 a 63 \\
Saturación & En zonas urbanas \\
Tamaño de pixel & 30 segundos de arco \\
Calibración radiométrica & Sin calibración \\
Bandas espectrales & 1 (Infrarrojos términos $10-12 \mathrm{um}$ ) \\
Sensibilidad a la radiación & Pancromática $500-900 \mathrm{~nm}$ \\
Hora nocturna de paso & $19: 30 \mathrm{~h}$ UTC \\
Cobertura de las imágenes & -180 a 180 grados longitud / -65 a \\
$\quad$ descargadas & 75 grados de latitud \\
Serie temporal (trabajados) & $1992-2002-2012$ \\
\hline
\end{tabular}

Fuente: Elaboración propia en base a Elvidge et al. (2013) y Checa et al. (2017).

La segunda fuente de datos empleada fueron imágenes del satélite Landsat 5 TM, escena Path: 225 Row: 84, (05 de enero de 1992) descargadas del Geoservidor Earth Explorer del United States Geological Survey (USGS, 2019).

Por último, para el desarrollo de las composiciones cartográficas fue necesario descargar las siguientes capas en formato shapefile (.SHP) provenientes del banco de datos abiertos del Instituto Geográfico Nacional (IGN, 2019):

- Departamentos / Partidos

- Provincias.

(https://ngdc.noaa.gov/eog/dmsp/downloadV4composites.html). Los archivos utilizados en la investigación corresponden a los nombrados como "avg_vis limpio" los cuales contienen las luces de ciudades, pueblos y otros sitios con iluminación persistente, incluidas las llamaradas de gas y descartando los eventos efímeros, como incendios. Se identificó el ruido de fondo y se reemplazó con valores de cero. Los valores de los datos oscilan entre 1 y 63 , siendo este último el máximo nivel de luz (NOAA, 2019). 


\section{Tratamiento de la información}

En esta etapa de la investigación se tuvieron en cuenta como referencia los trabajos desarrollados por el Grupo de investigación sobre Energía, Territorio y Sociedad de la Universitat Autónoma de Barcelona (Nel.lo et al., 2016; Checa et al., 2017; Checa \& Nel.1o, 2018).

El tratamiento digital de las imágenes y la elaboración de la cartografía se llevó a cabo en los softwares TerrSet versión 18.31 (Clark University, 2017) y QGIS versión 3.4.12 (QGIS Development Team, 2019). Una vez descargados los datos, se procedió a configurar el proyecto bajo el EPSG: 4326 (Coordenadas Geográficas - Datum WGS 84'), esto permitió tener toda la base de datos espacial unificada bajo un mismo sistema de referencia de coordenadas que facilitó la posterior combinación y análisis entre diferentes bases de datos espaciales. El paso siguiente fue realizar el recorte de las imágenes a la correspondiente área de estudio para lo cual fue necesario definir un cuadrante con las coordenadas extremas.

Como el objetivo de la investigación gira en torno al conocimiento de la extensión de la superficie urbana a partir de la superficie iluminada y, como no todos los píxeles con valores mayores que cero corresponden a las áreas de cobertura urbana, se estimó un valor mínimo (intensidad lumínica) de referencia ligado a diversas construcciones materiales humanas (Checa \& Nel.lo, 2018) ${ }^{4}$ que en el presente trabajo se denominan de manera amplia infraestructura gris. Para concretar este paso, era necesario contar con una capa de cobertura urbana que permitiera realizar una superposicion sobre las imágenes nocturnas y poder aproximar un valor mínimo como umbral de luminosidad urbana. Para extraer la cobertura urbana se realizó un proceso de clasificación no supervisada (ISOCLUST) ${ }^{5}$ para lo cual se especificaron 15 categorías a través de tres iteraciones sobre siete bandas de la imagen Landsat 5 TM, dicha técnica se encuentra dentro de los procedimientos de análisis por agrupamiento (cluster) y se ha utilizado de manera satisfactoria con objetivos similares (Da Silva et al., 2014).

Una vez lograda la cobertura urbana se realizó un proceso de extracción de los valores mínimos (Estadísticas de zona) y posteriormente se promediaron para llegar a establecer el valor del umbral de luz urbana en 44.41 .

A partir del valor de referencia se delimitó la superficie de luminosidad urbana en las imágenes de 1992, 2002 y 2012, tomandose en consideración aquellos píxles que tuvieran valores $\geq 44.41$.

Las imágenes resultantes de los procesos anteriores permitieron derivar los principales resultados de la investigación. Primero, se vectorizaron para luego calcular la

4 Esto no quiere decir, que los usos urbanos no se puedan extender en aquellas áreas con niveles de luz por debajo del valor de referencia establecido, como aclara Checa \& Nel.lo (2018) el concepto de luz urbana debe entenderse en terminos de intensidad más que de exclusión.

5 "ISOCLUST es un clasificador no supervisado auto-organizado iterativo basado en un concepto similar a la reconocida rutina ISODATA de Ball y Hall (1965) y a las rutinas de grupo como los procedimientos media-H y media-K" (Eastman, 2012). 
superficie $\left(\mathrm{km}^{2}\right)$ de luminosidad urbana. Esto a su vez, también permitió obtener los valores relativos de incremento de la superficie para cada una de las décadas analizadas.

La secuencia de pasos metodológico-técnico se encuentran explicitados en el diagrama de flujo de la Figura 1.

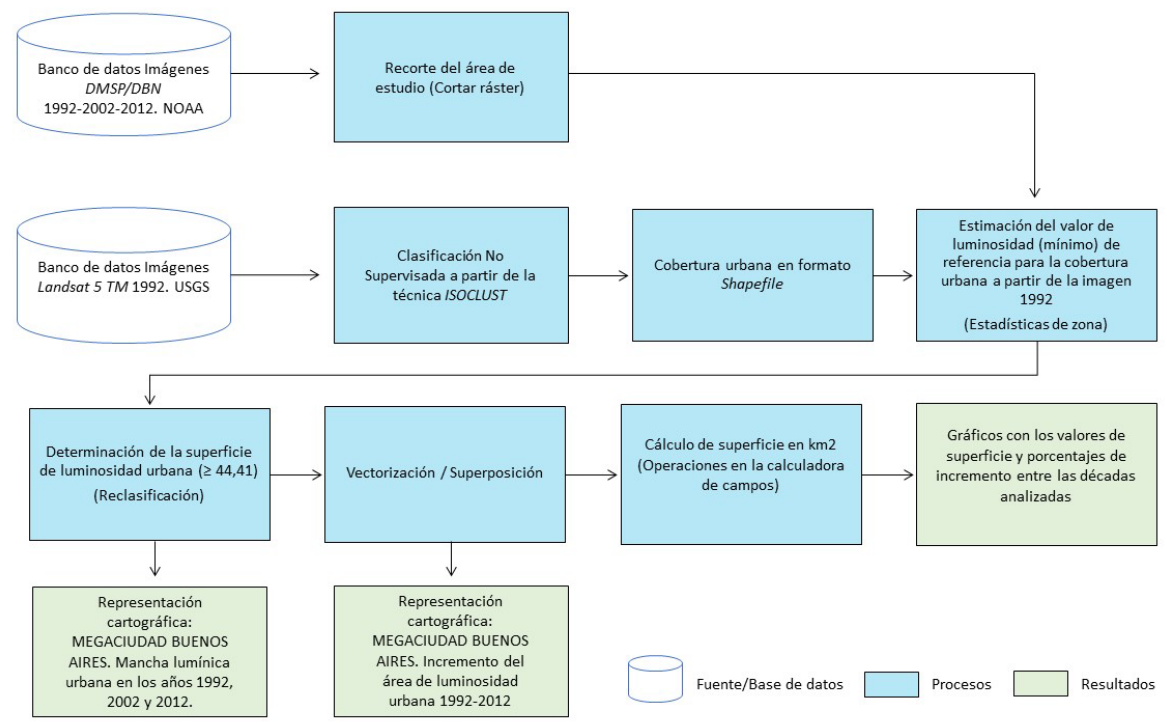

Figura 1. Diagrama de flujo de procedimientos.

\section{Aplicación}

\section{Área de estudio}

La gran mayoría de los estudios que intentan abarcar espacialmente a la principal área urbana argentina lo hacen a partir de considerar el concepto de Gran Buenos Aires (GBA) (INDEC, 2003) que incluye a la Ciudad Autónoma de Buenos Aires como ciudad central y 24 municipios de la Provincia de Buenos Aires que la rodean y forman una amplia superficie de conurbación. Considerando su vinculación con las áreas urbanas cercanas y separadas de la aglomeración central, la Dirección Provincial de Ordenamiento Urbano y Territorial (DPOUyT, 2007) la amplía, anexando 16 municipios a la tradicional definición de GBA, llevando su extensión a lo que fuera considerada la entidad funcional superando su definición física (aglomeración) y sus decenas de definiciones legales (municipios). 
Aunque son semicírculos por haberse desarrollado en el frente costero del río de la Plata, se considera que el GBA tiene un área central y se extiende mediante la superposición de tres anillos y ocho sectores de crecimiento representado por sus diferentes ejes de expansión (Buzai y Marcos, 2012). Su ampliación actual se produciría en un cuarto anillo, aunque a esa distancia el área urbana se desarrolla principalmente de manera sectorial.

Considerando la mayor amplitud, el presente trabajo considera la extensión de un radio teórico de $90 \mathrm{~km}$ desde el CBD y la última representación en escala 1:400 000. De esta manera queda definida una superficie que permite captar la extensión urbana en plenitud.

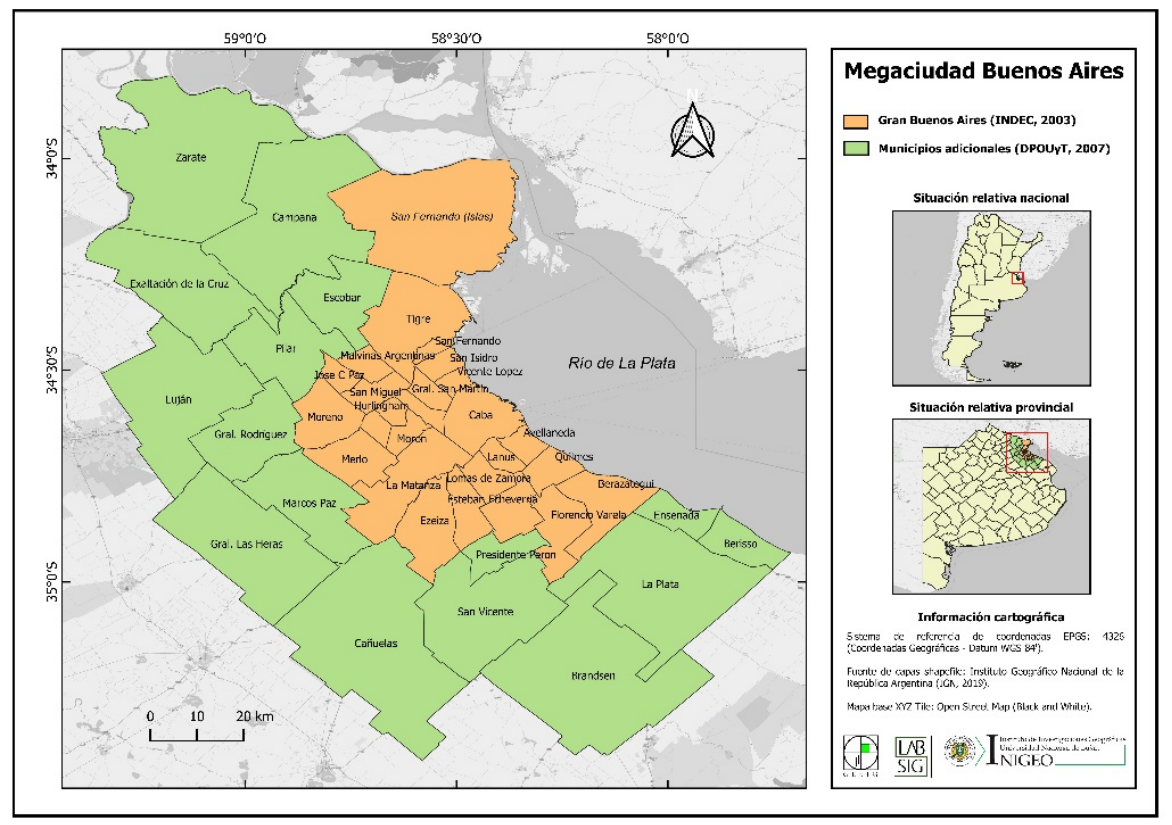

Figura 2. Área de estudio: Unidades espaciales municipales.

Expansión y conurbación: 1992, 2002 y 2012

El procesamiento digital de las imágenes satelitales nocturnas brindó como resultado las composiciones cartográficas presentadas en la Figura 3, en donde los valores que 
definen la aglomeración adquieren colores claros que representan las mayores luminosidades indicadoras de la infraestructura gris. ${ }^{6}$

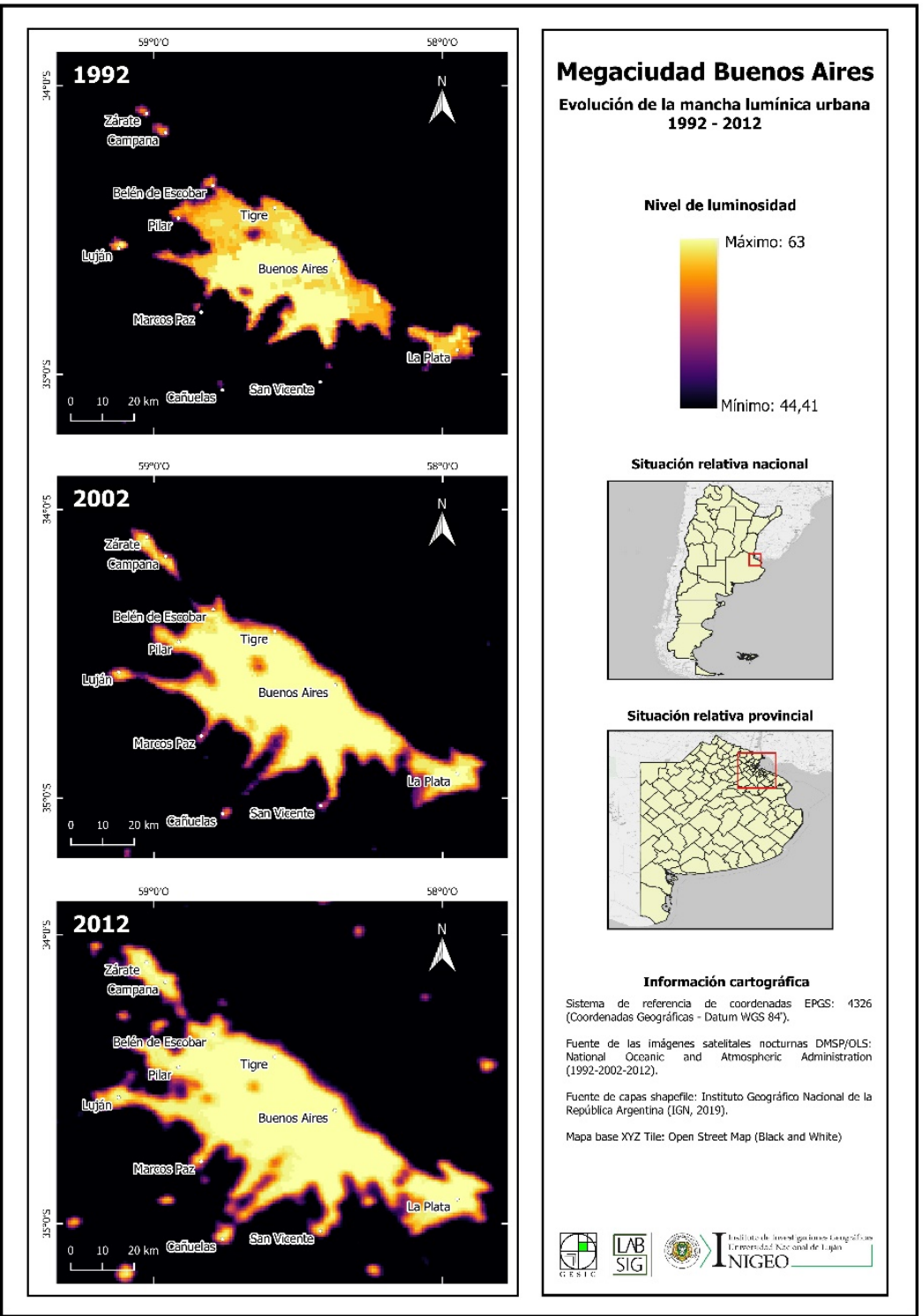

Figura 3. Procesamiento de imágenes satelitales nocturnas.

$6 \quad$ En este rango de valores es posible distinguir los niveles de actividad humana más altos, que para el caso del presente estudio se focaliza principalmente en las coberturas urbanas. 
En el año 1992, se aprecia un área urbana compacta con sectores lineales de crecimiento (denominados tentáculos). Todas las áreas urbanas cercanas a la Megaciudad Buenos Aires se encuentran claramente separadas. Esta situación que cambia en 2002 cuando se extienden la totalidad del crecimiento urbano lineal generando el último proceso de expansión con conurbación de sus ciudades cercanas para incorporarlas en la aglomeración central.

Estas anexiones se consolidan en el año 2012 y se convierten en la base para generar la cartografía síntesis, a partir de la superposición de capas de los diferentes años mediante el modelado cartográfico con SIG. De esta manera el mapa síntesis se convierte en la fuente empírica del proceso analizado y ámbito principal de interpretación.

\section{Cartografía síntesis}

El mapa final de la Figura 4, muestra el vínculo entre el análisis geográfico y la Cartografía. La primera apoyándose en los conceptos centrales del análisis espacial que se representan: 1) localización en la ubicación específica de cada localidad en el espacio absoluto, 2) distribución espacial en el reparto de todas las localidades en el área de estudio y la forma de la mancha urbana total, 3) asociación espacial entre la representación urbana y la base topográfica y 4) evolución espacial a partir de superponer los diferentes años (chess map) y generar valores de superficie para los diferentes períodos.

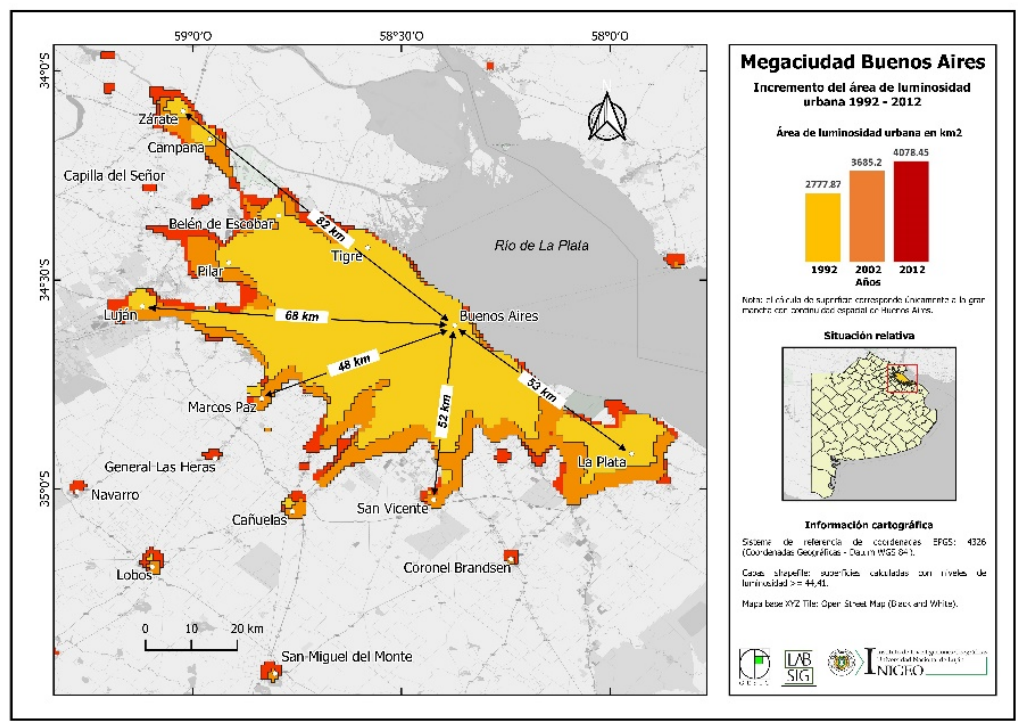

Figura 4. Megaciudad Buenos Aires. Cartografía síntesis de su último proceso de conurbación 
Los colores utilizados corresponden a una variable de tipo ordenada ya que se establece una relación de sucesión temporal en los diferentes años con mayor intensidad hacia la actualidad, espacialmente hacia la periferia extrema.

La aglomeración en 1992 es completa y luego se le anexan las superficies existentes hasta el 2002 y hasta el 2012. Contemplando el análisis realizado por Bertin (1988), el color se utiliza en el sentido de la variable visual valor ya que estos colores no solamente representan diferencias sino que principalmente establecen un ordenamiento para la sucesión temporal.

El color amarillo presenta la aglomeración en 1992, una gran ciudad compacta y áreas urbanas a su alrededor que quedan incluidas en la mancha urbana en diferentes momentos. En la década 1992-2002, en naranja, se anexan ciudades en cuatro ejes: Luján (oeste), Marcos Paz (sudoeste), San Vicente (sur) y Gran La Plata (sudeste) y en la década 2002-2012, en rojo, en un eje: Zarate-Campana (Noroeste). Este último es el más lejano, allí la Megaciudad Buenos Aires llega a una expansión de $90 \mathrm{~km}$ dentro de un promedio de $61 \mathrm{~km}$ para la totalidad de anexiones. Los valores poblacionales incluidos se presentan en la Tabla 2. El incremento de la superficie lumínica urbana fue de un $32.69 \%$ en la década 1992-2002, mientras que, para la década de $2002-2012$ fue de un $10.67 \%$.

Tabla 2

Población de las recientes áreas urbanas conurbadas

\begin{tabular}{llr}
\hline \multicolumn{1}{c}{ Área urbana } & \multicolumn{1}{c}{ Rango } & Población \\
\hline Gran La Plata* & Área urbana conturbada & 787.294 \\
Luján & Ciudad de tamaño intermedio & 67.266 \\
Marcos Paz & Ciudad de tamaño intermédio & 50.460 \\
San Vicente & Ciudad pequena & 21.411 \\
Zárate-Campana & Ciudad doble (aglomeración) & 185.382 \\
\hline & Total & 1.111 .813 \\
\hline
\end{tabular}

* La Plata, Berisso y Ensenada.

Fuente: $\quad$ Elaboración propia en base al Censo Nacional de Población, Hogares y Viviendas, 2010.

De acuerdo a los reportes presentados por Naciones Unidas (UN, 2014, 2018) la población de la Megaciudad Buenos Aires evolucionó en las últimas décadas, en millones de habitantes, de la siguiente manera: 2000 (12.50), 2010 (15.00) y 2018 (14.97) con proyección al 2030 (16.50). Esto indica que de acuerdo a la última 
conurbación en el año 2010 ya estaría a superando los 16 millones de habitantes ${ }^{7}$ en una superficie aproximada de $4000 \mathrm{~km}^{2}$ con una densidad de población: $4000 \mathrm{hab} / \mathrm{km}^{2}$.

\section{Consideraciones finales}

El trabajo realizado constituye un aporte del análisis espacial basado en el procesamiento digital de imágenes satelitales nocturnas y SIG aplicados al estudio de la estructura del espacio geográfico y su evolución, poniendo su foco de atención en la expansión urbana para el descubrimiento de situaciones actuales y tendencias futuras.

Las manifestaciones espaciales de diversas relaciones sociales brindan la posibilidad de abordar el estudio de la materialidad empírica en la escala humana de un sistema complejo. El espacio geográfico manifestado por la superficie terrestre es el nivel focal y allí son aplicados los principales conceptos del análisis espacial mediante el uso de las actuales geotecnologías.

En este marco la confluencia entre teoría, metodología y técnicas de análisis espacial permitieron llegar a una novedosa comprobación sobre la evolución espacial reciente de la Megaciudad Buenos Aires.

Durante el cambio de siglo pudo verificarse que su último crecimiento se transformó en un notable proceso de conurbación que incorporó en la aglomeración central seis áreas urbanas que rodeaban sus bordes a distancias de entre $42 \mathrm{~km}$ y $82 \mathrm{~km}$ del CDB, de esta manera, la Megaciudad Buenos Aires experimentó una nueva expansión con sectores de conurbación.

Las imágenes satelitales nocturnas, permiten obtener una novedosa visión de la aglomeración a partir de mostrar claramente el espacio adaptado y sistema de flujos bajo el concepto de infraestructura gris. Surge claramente la materialidad empírica en su máxima expresión, motivo por el cual mediante su uso fue posible tener una clara perspectiva de la tendencia del alcance urbano. Esto brinda nuevas dimensiones a la megaciudad en distancias, superficies y valores poblacionales, además de mostrar su dinamismo ante un crecimiento urbano mixto, que se hace evidente ante la evolución conjunta del crecimiento por urbanizaciones cerradas (dispersa) y la conurbación (compacta) en la periferia extrema.

La Megaciudad Buenos Aires es un importante ejemplo del desarrollo urbano de una de las mayores áreas urbanas de América Latina en el marco socio-económico y político de la actual globalización.

7 Coincidente con la aproximación de City Population (2019) donde consignan la Megaciudad Buenos Aires (incluido La Plata) con 16.3 millones de habitantes. 


\section{Bibliografía}

Amaral, S., Monteiro, A.M., Camara, G. \& Quintanilha, J.A. (2006). "DMSP/OLS night-time light imagery for urban population estimates in the Brazilian Amazon", International Journal of Remote Sensing, 27(5): 855-870. DOI:10.1080/01431160500181861

Auge, M. (2017). Los no lugares. Espacios del anonimato, Gedisa, Barcelona.

Bähr, J. (1976). "Neuere Entwicklungstendenzen lateinamerikanischer Grosstädte", Geographische Rundschau, 28(4): 125-133.

Bähr, J. \& Mertins, G. (1982). "A model of the social and spatial differentiation of Latin American Metropolitan cities", Applied Geography and Development, 19: 22-45.

Batty, M. \& Longley, P. (1994). Fractal Cities, Academic Press, London.

Bauer, I. (1993). “Le 'suburbia', sommes-nous concernés?”, Urbanisme, 1: 67-88.

Benedict, M.A. \& McMahon, E.T. (2006). Green Infraestructure. Linking Landscapes and Communities, Washington, Island Press.

Berry, B.J.L. (1976). Urbanization and counterurbanization, New York, Arnold. - (1985). "Islands of renewal in seas of decay", in Peterson, P.E. (ed.), The New Urban Reality, Washington, The Brookings Institution, pp. 69-96.

Bertalanffy, L. von (1968). General System Theory, George Brazilier, New York.

Bertin, J. (1988). La gráfica y el tratamiento gráfico de la información, Madrid, Taurus Ediciones.

Borsdorf, A. (1982). "Die lateinamerikanische Grosstadt. Zwischenbericht zur Diskussion um ein Modell”, Geographische Rundschau, 34: 498-501.

Borsdorf, A. (1994). "Die Stadt in Lateinamerika. Kulturelle Identität und urbane Probleme", Geographie und Schule, 89: 3-12.

Borsdorf, A. \& Coy, M. (2009). "Megacities and Global Change: Case Sudies from Latin America", Die Erde, 140(4): 1-20.

Bunge, M. (2012). A la caza de la realidad. La controversia sobre el realismo, Barcelona, Gedisa.

Burgess, E.W. (1925). "The growth of the city: an introduction to a research project", in R.E. Park, E.W. Burguess \& R.D. McKenzie (ed.), The City, Chicago, University of Chicago Press, pp. 47-62.

Buzai, G.D. (1992) "El desplazamiento suburbano de los grupos sociales de alto nivel económico: el caso de Buenos Aires”, Análisis Geográfico, 4(8): 25-34.

- (2014). Mapas Sociales Urbanos, Buenos Aires, lugar editorial.

(2015a). "Sistemas de Información Geográfica, 50 años, Boletín Red GESIG, 1: 2-3. 
(2015b). "Urban models in the study of Latin American cities", Innsbrucker Geographische Studien, 40: 271-288.

Buzai, G.D. \& Baxendale, C.A. (1998). "Buenos Aires (1869-1991). La geometría urbana como representación de una historia económica y sociodemográfica", Signos Universitarios, 18(34): 71-88.

Buzai, G.D. \& Lanzelotti, S.L. (dir.) (2019). Atlas de Geografía Humana de la cuenca del río Luján, Luján, Instituto de Investigaciones Geográficas.

Buzai, G.D., Lemarchand, G.; \& Schuschny, A. (1998)." Aplicación de la geometría fractal al estudio del medio ambiente y las geociencias", en Matteucci, S.D.; Buzai, G.D. (eds.), Sistemas Ambientales Complejos: herramientas de análisis espacial, Buenos Aires, Eudeba, pp. 347-364.

Buzai, G.D. \& Marcos, M. (2012). "The social map of greater Buenos Aires as empirical evidence of urban models", Journal of Latin American Geography, 11(1): 67-78.

Buzai, G.D. \& Ruiz, E. (2012). "Geotecnósfera. Tecnologías de la Información Geográfica en el contexto global del sistema mundo", Anekumene, 4: 88-106.

Carter, H. (1983). El estudio de la Geografia Urbana, Madrid, IEAL.

Checa, J., \& Nel.lo, O. (2018). "Urban Intensities. The Urbanization of the Iberian Mediterranean Coast in the Light of Nighttime Satellite Images of the Earth", Urban Science, 2(4): 1-17. https://doi.org/10.3390/urbansci2040115.

Checa, J., Gomà, A., López, J., Martín, J., \& Nel.lo, O. (2017). “Energía y proceso de urbanización en España. Nuevas perspectivas de investigación a partir de la imagen satelital nocturna de la tierra”, en M. Zaar, M. Vasconselos, \& H. Capel (eds.), La electrificación y el territorio. Historia y futuro, Barcelona, Universitat de Barcelona, pp. 1-20. Recuperado de http://www.ub.edu/geocrit/Electr-yterritorio/ChecaGoma.pdf

City Population (2019). Major Agglomerations of the World. Recuperado de https://www.citypopulation.de/world/Agglomerations.html

Clark University. (2017). TerrSet. Versión 18.31. Massachusetts, Clark Labs.

Da Silva, C.J., Insaurralde, J.A., \& Cardozo, O.D. (2014). "Cartografía de coberturas del suelo mediante sensores remotos, de la ciudad de Resistencia", Argentina (2013). Revista Geográfica Digital, 11(21): 1-18. https://doi.org/10.30972/geo.11212103

Dobson, J.E. (1983) “Automated Geography”, The Professional Geographer, 35(2): 135-143.

DPOUyT (2007). Lineamientos Estratégicos para la Región Metropolitana de Buenos Aires, La Plata, Dirección Provincial de Ordenamiento Urbano y Territorial de la Provincia de Buenos Aires. 
Elvidge, C.D., Baugh, K., Zhizhin, M. \& Chi Hsu, F. (2013). "Why VIIRS data are superior to DMSP for mapping nighttime lights", in Proceedings of the AsiaPacific Advanced Network, 35: 62-69. https://doi.org/10.7125/APAN.35.7

Elvidge, C.D., Baugh, K., Zhizhin, M., Chi Hsu, F. \& Ghosh, T. (2017). "VIIRS night-time lights", International Journal of Remote Sensing, 38(21): 5860-5879. https://doi.org/10.1080/01431161.2017.1342050

Eastman, R.J. (2012). Idrisi selva. Guía para SIG y procesamiento de imágenes, Massachusetts, Clark University.

Ford, L. (1996). "A new and Improved Model of Latin american City Structure", Geographical Review, 86(3): 437-440.

García, R. (2006). Sistemas complejos, Barcelona, Gedisa.

Griffin, E. \& Ford, L. (1980). “A model of Latin American city structure”, Geographical Review, 70(4): 397-422.

Harris, C.D. \& Ullman, E.L. (1945). "The nature of cities", The Annals of the American Academy of Political and Social Sciences, 242: 7-17.

Henderson, M., Yeh, E.T., Gong, P., Elvidge, C. \& Baugh, K. (2003). "Validation of urban boundaries derived from global night-time satellite imagery", International Journal of Remote Sensing, 24(3): 595-609. https://doi.org/10.1080/01431160304982

Hoyt, H. (1939). The Structure and Growth of Residential Neighborhoods in American Cities, Washington, Federal Housing Administration.

Instituto Geográfico Nacional —IGN (2019). Datos abiertos. Capas SIG. Recuperado de https:/www.ign.gob.ar/NuestrasActividades/InformacionGeoespacial/CapasSIG Instituto Nacional de Estadística y Censos - INDEC (2003). ¿Qué es el Gran Buenos Aires?, Buenos Aires, Publicaciones del INDEC. Recuperado el 15 de junio de 2019, de https://web.archive.org/web/20101113161116;

http://www.indec.gov.ar/nuevaweb/cuadros/4/folleto\%20GBA.pdf

(1 de noviembre de 2019). Estadísticas de población. Recuperado de https://www.indec.gob.ar/

Indovina, F. (2009). Dalla cittá diffusa all'archipielago metropolitano, Milano, Franco Angeli.

Janoschka, M. (2002). "Stadt der Inseln" Buenos Aires: Abschottung und Fragmentierung als Kennzeichen einer neuen Stadtmodells“, RaumPlanung, 101: 65-70.

Kamarajugedda, S.A.; Mandapaka, P.V. \& Lo, E.Y. (2017). "Assessing urban growth dynamics of major Southeast Asian cities using night-time light data", International Journal of Remote Sensing, 38(21): 6073-6093. https://doi.org/10.1080/01431161.2017.1346846 
Liu, L. \& Leung, Y. (2015). “A study of urban expansion of prefectural-level cities in South China using night-time light images", International Journal of Remote Sensing, 36: 5557-5575. https://doi.org/10.1080/01431161.2015.1101650

Martin Oriol, J. (2016). "Observing changes in urban form through night satellite images in Buenos Aires and Lima", en O. Nel.lo \& R. Mele (eds.), Cities in the 21st Century, London and New York, Routledge, pp. 93-95.

Mertins, G. (1980). "Typen inner- und randstädtischer Elendsviertel in Grosstädten des andinene Südamerika", Lateinamerika Studien, 7: 269-295.

Mitchell, J.G. (2001). "La expansión urbana”, National Geographic, 9(1): 82-105.

Montes Galbán, E. (2017). "Ideas sobre tecnociencia y experimentación digital en geografía", Vientos del Norte, 2: 7-17. Recuperado de

http://editorial.unca.edu.ar/Publicacione $\% 20$ on $\% 20$ line/CD $\% 20$ VIENTOS $\% 202$ 017/PDF/N5\%20Vol\%20II/1-Ideas\%20sobre\%20tecnociencia.pdf

(2019). "Cuenca. Luminosidad nocturna”, en G.D. Buzai \& S.L. Lanzelotti (dir.), Atlas de Geografia Humana de la cuenca del río Luján, Luján, Instituto de Investigaciones Geográficas, pp. 168-169.

- (2020). "Expansión y densificación urbana del Gran Buenos Aires (20122019) a partir de imágenes satelitales nocturnas", Revista Geográfica Digital, en prensa.

Morello, J., Buzai, G., Baxendale, C.A., Matteucci, S.D., Rodríguez, A., Godagnone, R.E. \& Casas, R.R. (2000). "Urbanización y consumo de tierra fértil", Ciencia hoy, 18(65): 50-61.

National Geographic (1998). Población y recursos [Mapa]. 1:54.109.440, Washington, D.C., National Geographic Maps.

(2004). La tierra de noche [Mapa]. 1:46.360.000, Washington, D.C., National Geographic Maps.

- (2005). África la huella humana [Mapa]. 1:14.636.000. Washington, D.C., National Geographic Maps.

Nel.lo, O., López Redondo, J., Martín Oriol, J. \& Checa Rius, J. (2016). La luz de la ciudad. El proceso de urbanización en España a partir de las imágenes nocturnas de la Tierra, Barcelona, Universitat Autónoma de Barcelona.

Nel.lo, O., López, J., Martín, J. \& Checa, J. (2017). "Energy and urban form. The growth of European cities on the basis ofnight-time brightness", Land Use Policy, 61: 103-112. https://doi.org/10.1016/j.landusepol.2016.11.007

National Oceanic and Atmospheric Administration -NOAA (2019). Version 4 DMSP-OLS Nighttime Lights Time Series. Recuperado de https://ngdc.noaa.gov/eog/dmsp/downloadV4composites.html 
Pérez Machado, R.P.; Vizeu Barrozo, L., Luchiari, A. \& Small, C. (2014). "Identification of the urban continuum of Sao Paulo Metropolitan Agglomeration with people, lights and land use. First results of a methodological approach", Annual Conference of the IGU Urban Commission Poznan, IGU, pp. 1-42. Recuperado de https://www.researchgate.net/publication/266202035 Identification of the urb an continuum of Sao Paulo Metropolitan Agglomeration with people lights and land use First_results_of_a methodological_approach

Potere, D.; Schneider, A., Angel, S. \& Civco, D. L. (2009). "Mapping urban areas on a global scale: which of the eight maps now available is more accurate?", International Journal of Remote Sensing, 30: 6531-6558.

https://doi.org/10.1080/01431160903121134

QGIS Development Team (1 de noviembre de 2019). QGIS. Un Sistema de Información Geográfica libre $y$ de Código Abierto. Recuperado de https://qgis.org/es/site/

Quaíni, K. (2014). Procedimiento metodológico para la generación de mapas de interfase urbano-vegetación rural, Córdoba, Proyecto BPR-BID.

Rosnay, J. de (1977). El macroscopio. Hacia una visión global, Madrid, AC.

Roy Chowdhury, P.K., Maithani, S. \& Dadhwal, V.K. (2012). "Estimation of urban population in Indo-Gangetic Plains using night-time OLS data", International Journal of Remote Sensing, 33: 2498-2515. https://doi.org/10.1080/01431161.2011.616550

Schnore, L.F. (1965). "On the spatial structure of cities in the two Americas", en Ph. M. Hauser and L.F. Schnore (eds.), The Study of Urbanization, New York, John Wiley \& Sons.

Sjoberg, G. (1960). The Preindustrial City. Past and Present, Glencoe, Free Press.

Soja, E. (2000). Posmetropolis. Critical studies of cities and regions, Oxford, Blackwell.

Small, C., Pozzi, F. \& Elvidge, C.D. (2005). Spatial analysis of global urban extent from DMSP-OLS night lights, 96: 277-291.

https://doi.org/10.1016/j.rse.2005.02.002

United Nations -UN (2014). Urban Aglomerations 2014, New York, Department of Economic and Social Affairs, Population Division.

(2018). The World's Cities in 2018 - Data Booklet. New York, Department of Economic and Social Affairs, Population Division.

United States Geological Survey -USGS (2019). Earth Explorer, Recuperado de https://earthexplorer.usgs.gov/ 
Xin, X., Liu, B., Di, K., Zhu, Z., Zhao, Z., Liu, J., Zhang, G. (2017). "Monitoring urban expansion using time series of night-time light data: a case study in Wuhan, China", International Journal of Remote Sensing, 38(21): 6110-6128. https://doi.org/10.1080/01431161.2017.1312623

Whyte, W. (1958). "Urban Sprawl”, in The Editors of Fortune. The Exploding Metropolis: A Study of the Assault on Urbanism and How Our Cities Can Resist It, New York, Anchor Books.

Zhou, Y., Smith, S.J., Zhao, K., Imhoff, M., Thomson, A., Bond-Lamberty, B. \& Elvidge, C.D. (2015). "A global map of urban extent from nightlights", 10(5): 1-11. https://doi.org/10.1088/1748-9326/10/5/054011 